\title{
Dr. Jochen Aumiller zum siebzigsten Geburtstag
}

\author{
Am 11. Oktober dieses Jahres feiert Dr. Jochen Aumiller seinen \\ 70. Geburtstag. Als Chefredakteur der MMW hat er zwischen \\ 1977 und 1998 Maßstäbe an journalistischer und wissenschaft- \\ licher Qualität gesetzt.
}

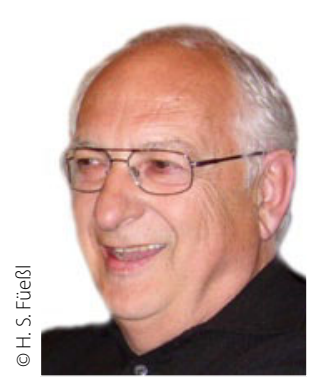

Bereits in der Schulzeit in Niederbayern ließ Jochen Aumiller seine herausragenden Fähigkeiten für journalistisches Schreiben und Fotografieren erkennen. Während eines Volontariates bei der Deggendorfer Zeitung erlernte er das Handwerk von der Pike auf und bestand bravourös den journalistischen Härtetest, in einer ereignisarmen niederbayerischen Provinzstadt täglich eine Seite füllen zu müssen! Auch während des Medizinstudiums in München konnte er die Finger nicht vom Journalismus lassen. In den 1970-er Jahren wurde er als Autor und Moderator von Wissenschaftssendungen im Bayerischen Rundfunk bereits einer breiteren Öffentlichkeit bekannt. Nach einem Intermezzo in der Anästhesie trat er 1972 als Redakteur bei der Zeitschrift "Ärztliche Praxis" ein. Als die Verlagsgruppe Bertelsmann für ihr medizinisches Flaggschiff MMW in der Nachfolge des großen Walter Trummert einen Chefredakteur suchte, fiel die Wahl auf Jochen Aumiller.

Unter der 21-jährigen Stabführung von Dr. Jochen Aumiller als Chefredakteur erlebte die MMW zahlreiche Wandlungen und Relaunches, wie es eben der Geschmack der Zeit erforderte. Oberste und unveränderte Prämisse blieb aber immer der Dreiklang zwischen Wissenschaftlichkeit, Praxisorientierung und Lesefreundlichkeit. Aumillers unermüdliches Feilen an der inhaltlichen und journalistischen Qualität fand auch die Anerkennung einschlägiger Fachgesellschaften: 1982 wurde ihm der Walter-Trummert-Preis der Vereinigung der Deutschen Medizinischen Fach- und Standespresse e. V., 1995 der Preis für Medizinpublizistik der Deutschen Hochdruckliga e. V. verliehen.

Mit feinem Gespür für epidemiologische Trends war Jochen Aumiller seiner Zeit oft weit voraus. Zeugnis hierfür sind seine Plethora von Sonderpublikationen, die Gründungen von neuen Zeitschriften wie der "Cardio News" oder des "Allergo Journals" und erste Versuche, ärztliche Fortbildung auch über das Fernsehen zu organisieren. Die Kardiologie hat es ihm besonders angetan. Rastlos umrundete er den Globus, um von allen großen kardiologischen Kongressen aus erster Hand zu berichten. Durch seine liebenswürdige und charmante Art, verbunden mit penibler journalistischer Sorgfalt, verstand er es, das Vertrauen wichtiger Meinungsbildner zu gewinnen und kompetente Fachautoren immer wieder aufs Neue zu motivieren, für seine Zeitschrift tätig zu werden. Dass die MMW heute einer der führenden Fortbildungstitel in Deutschland ist, verdankt sie auch Jochen Aumiller. Redaktion und Schriftleitung wünschen alles Gute.

Ad multos annos!

PROF. DR. MED. H. S. FÜESSL . 